\title{
Adenoma of Minor Vestibular Glands
}

National Cancer Institute

\section{Source}

National Cancer Institute. Adenoma of Minor Vestibular Glands. NCI Thesaurus. Code C40301.

A rare, benign neoplasm that arises from the vulva It is characterized by the presence of clusters of small glands lined by mucinous epithelial cells. Bartholin duct structures are not present. 